\title{
Radioablation of Hepatic Metastases from Renal Cell Carcinoma With Image-guided Interstitial Brachytherapy
}

\author{
JAZAN OMARI ${ }^{1}$, CONSTANZE HEINZE ${ }^{1}$, ROBERT DAMM ${ }^{1}$, PETER HASS $^{2}$, ANDREAS JANITZKY ${ }^{3}$, \\ JOHANN JAKOB WENDLER ${ }^{3}$, MAX SEIDENSTICKER ${ }^{4}$, JENS RICKE ${ }^{4}$, MACIEJ J. POWERSKI ${ }^{1}$ and MACIEJ PECH ${ }^{1,5}$ \\ Departments of ${ }^{1}$ Radiology and Nuclear Medicine, ${ }^{2}$ Radiation Oncology, and ${ }^{3}$ Urology, \\ Otto-von-Guericke University, Magdeburg, Germany; \\ ${ }^{4}$ Department of Radiology, University Hospital Munich, Munich, Germany; \\ ${ }^{5}$ Second Department of Radiology, Medical University of Gdansk, Gdansk, Poland
}

\begin{abstract}
Background/Aim: High-dose-rate interstitial brachytherapy (iBT) has been shown to provide high tumor control rates in the treatment of primary or secondary malignancies at various sites. The objective of this study was to evaluate the efficacy and safety of image-guided iBT in patients with metastatic renal cell carcinoma (mRCC). Materials and Methods: A total of 14 patients with a cumulative number of 54 unresectable RCC liver metastases after treatment with computed tomography $(C T)$ - or open magnetic resonance imaging (MRI)-guided iBT using an iridium-192 source (single fraction irradiation) were included in this retrospective study. Results: Local tumor control rate was $92.6 \%$ during a median follow-up of 10.2 months (range=2.4-73.6 months). Median progression-free survival after $i B T$ was 3.4 months (range $=1.0-27.8$ months). Median overall survival was 51.2 months (range $=10.2-81.5$ months). No severe adverse events (grade 3 or more) were recorded. Conclusion: Image-guided $i B T$ is a safe and feasible treatment in patients with $m R C C$.
\end{abstract}

Renal cell carcinoma (RCC) represents the sixth most common cancer in men and the tenth in woman with a rising incidence, presumably due to the more frequent incidental diagnoses of small indolent cancers $(1,2)$. However, locally advanced disease continues to be diagnosed in a notable proportion of patients, with up to $17-20 \%$ of all RCC being initially diagnosed with synchronous distant metastases and $40-50 \%$ of those with localized advanced disease will ultimately progress

Correspondence to: Department of Radiology and Nuclear Medicine, Otto-von-Guericke University, Leipziger Strasse 44, 39120 Magdeburg, Germany. Tel: +49 3916713030, Fax: +49 3916713029, e-mail: Jazan.Omari@med.ovgu.de

Key Words: Renal cell carcinoma, metastases, interventional oncology, image-guided intervention, interstitial brachytherapy. to metastatic disease (3). Without treatment the prognosis of patients with advanced or metastasized RCC (stage IV) is poor with a median survival of 6 to 12 months and a 5-year survival rate of less than $20 \%$ (4).

Due to the improved understanding of the molecular biology and genomics of RCC, the systemic treatment for metastasized RCC (mRCC) shifted over the last 15 years from a non-specific immune approach (cytokine era) to targeted therapy e.g. against vascular growth factor (VGEF), and to novel immunotherapy agents (e.g. immune-checkpoint inhibitors) (5). Impressive anti-tumor effects and prolongation of survival in patients with advanced or mRCC have been shown after treatment with these agents, for instance, VEGF tyrosine kinase inhibitor monotherapy has now been the standard first-line therapy for naïve metastatic patients, with a median overall survival of 22.9-26.4 months $(6,7)$. Despite their efficacy, these agents might also reduce patients' quality-of-life by causing severe adverse events (grade 3 and 4). For example, sunitinib, compared to pazopanib, causes a higher incidence of fatigue (17\% versus $10 \%)$, hand-foot syndrome $(11 \%$ versus $6 \%)$ and hematological toxicities (14-22\% versus <1\%) (8).

In the cytokine era, cytoreductive nephrectomy was recommended in metastatic patients with a good performance status, prior to treatment with systemic therapy. Due to the development of targeted therapies the median overall survival in patients with stage IV RCC has been extended $(9,10)$, hence, according to the Guidelines from the European Society for Medical Oncology (ESMO) the recommendation for nephrectomy in these patients is currently being reconsidered and only given under restricted conditions (11). Furthermore, the ESMO-guideline suggests metastasectomy and other local treatment strategies for selected patients after assessment by a multidisciplinary team (11). A recent systematic review of 16 studies including 2,350 patients sought to investigate the benefit of various local treatments of metastases from RCC (12). The results consistently suggest that patients treated 
with complete metastasectomy have better survival and symptom control than those treated with either incomplete or no metastasectomy (12). But the guideline does not state a general recommendation on whether a patient should be referred for local treatment or not.

However, in many cases surgery might not be possible due to the distribution or volume of the metastatic lesions or due to a poor performance status, apart from the surgery-associated morbidity and mortality. Aside from surgical resection, a multidisciplinary approach to localized therapy might also include image-guided local ablation techniques such as radiofrequency ablation (RFA) or interstitial brachytherapy (iBT). In iBT, an iridium-192 source is temporarily implanted into the metastatic lesions via percutaneously inserted applicators, which are placed under imaging guidance with a minimally invasive intervention. This technique enables a delineated single-fraction irradiation of the target volume. iBT has already been shown to be an efficient and mild treatment, with a minimum of complications, in ablation of primary or secondary malignancies at various sites (13-17). To our knowledge, no study has assessed the feasibility of iBT in the treatment of mRCC. The purpose of this retrospective study was to evaluate safety and efficacy of image-guided iBT in a cohort of patients with unresectable mRCC.

\section{Materials and Methods}

Eligibility criteria and patient population. Patient recruitment was carried out in our department between June 2006 and March 2017. A total of 14 patients ( 9 males and 5 females; mean age 65.1 years; range $=44-78$ years) with histologically proven RCC with a total of 54 liver metastases were enrolled in this retrospective analysis. All patients displayed metastatic tumor progression at the time of referral to our department and every case was discussed in an interdisciplinary tumor conference prior to iBT. Decision for iBT was taken when: (a) surgical resection was impossible or unfavorable, assessed by a surgeon with expertise in the field of visceral surgery, (b) there was contraindication for resection or severe comorbidities, (c) patient refused surgery, $(\mathrm{d})$ oligometastatic disease was present $(\leq 5$ metastatic lesions, but more importantly amendable for regional treatment aimed at a complete ablation), (d) East Coast Oncology Group (ECOG) performance status below 2, (e) adequate coagulation parameters (platelet count $>50,000 / \mathrm{nl}$, international normalized ratio $=\mathrm{INR}>1.5$, partial thromboplastin time $<50 \mathrm{sec}$ ). No upper limit concerning the maximum tumor diameter was placed.

Prior to iBT all patients underwent nephrectomy (13/14) or partial nephrectomy (1/14). Overall, 11 out of 14 patients received first and/or second-line systemic treatment (i.e. 9/11 sunitinib, 2/11 sorafenib, 2/11 interleukin2, 2/11 Avastin, 3/11 Roferon, 2/11 temsirolimus, $1 / 11$ mitomycin, $1 / 11$ axitinib).

Three patients did not receive any systemic anticancer treatment due to reduced general condition, comorbidities or refusal of systemic treatment. A total of 5/14 patients underwent local ablation of RCC metastases prior to iBT (including local ablation using iBT or radiofrequency ablation of lung or lymph nodes metastases, or radioembolization of the liver; for detailed patient characteristics see Table I).
Table I. Patient characteristics.

\begin{tabular}{|c|c|}
\hline \multicolumn{2}{|l|}{ Patient characteristics } \\
\hline Total number of Patients & 14 \\
\hline \multicolumn{2}{|l|}{ Patient gender } \\
\hline Men & 9 \\
\hline Women & 5 \\
\hline \multicolumn{2}{|l|}{ Age at time of diagnosis $(y)$} \\
\hline Mean & 65.1 \\
\hline Range & $44-78$ \\
\hline \multicolumn{2}{|l|}{ Treatment of primary tumor } \\
\hline Total nephrectomy & 13 \\
\hline Partial nephrectomy & 1 \\
\hline \multicolumn{2}{|l|}{ Distant metastases } \\
\hline Metachronous & 11 \\
\hline Synchronous & 3 \\
\hline Patients received systemic treatment before iBT (n) & 11 \\
\hline Sunitinib & 9 \\
\hline Sorafenib & 2 \\
\hline Interleukin-2 & 2 \\
\hline Avastin & 2 \\
\hline Roferon & 3 \\
\hline Temsirolimus & 2 \\
\hline Mytomycin & 1 \\
\hline Axitinib & 1 \\
\hline \multicolumn{2}{|l|}{ localized metastatic treatment prior to $\mathrm{iBT}$} \\
\hline Radioembolization of the liver & 3 \\
\hline Radiofrequency ablation of the liver & 1 \\
\hline Radiation of mediastinal lymph node metastases & 2 \\
\hline Total number of target lesions (n) & 54 \\
\hline \multicolumn{2}{|l|}{ BT image guidance } \\
\hline $\mathrm{CT}$ & 29 \\
\hline MRT & 25 \\
\hline \multicolumn{2}{|l|}{ Diameter of target lesion $(\mathrm{cm})$} \\
\hline Median (range) & $1.8(0.5-13.9)$ \\
\hline \multicolumn{2}{|l|}{ Number of catheters/lesions } \\
\hline Median (range) & $1(1-9)$ \\
\hline \multicolumn{2}{|l|}{ Irradiation Dose BT (Gy) } \\
\hline Median (range) & $16.1(6.5-27.35)$ \\
\hline \multicolumn{2}{|l|}{ Irradiation Time BT $(\mathrm{min})$} \\
\hline Median (range) & $22.93(7.0-92.32)$ \\
\hline \multicolumn{2}{|l|}{ Local tumor control (months) } \\
\hline Median (range) & $10.2(2.4-73.6)$ \\
\hline \multicolumn{2}{|l|}{ Time to progression (months) } \\
\hline Median (range) & $3.4(1.0-27.8)$ \\
\hline \multicolumn{2}{|l|}{ Overall survival } \\
\hline Median (range) & $51.2(10.2-82.5)$ \\
\hline
\end{tabular}

Patient No.4, treated in April 2016, was diagnosed with RCC of the left kidney in 1993 and a metachronous contralateral RCC in January 2014. Pre-intervention, all patients underwent a full clinical status evaluation with a physical examination and laboratory assessment. Additionally, imaging was performed using a wholebody contrast-enhanced computed tomography (CT) scan and a gadolinium (Gb)-EOB-DTPA-enhanced magnetic resonance imaging (MRI) of the liver (Primovist $^{\circledR}$, Bayer, Pharma, Leverkusen, Germany). The ethics committee of the Otto-vonGuericke-University Magdeburg approved the analysis of the patient data (Approval number: 177/18) and informed consent was obtained from all individual participants included in the study. 

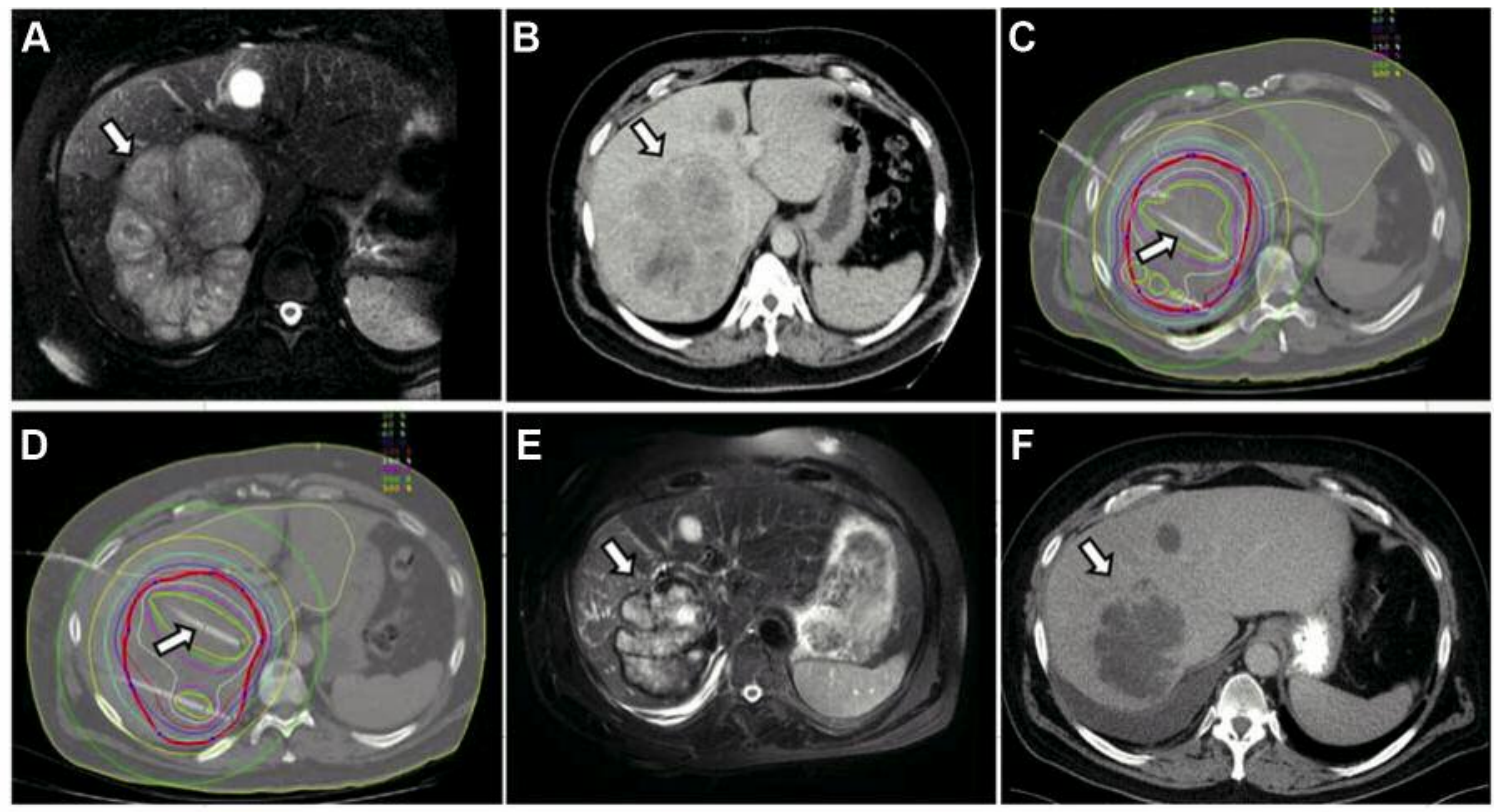

Figure 1. Local tumor control in a patient with metastatic renal cell carcinoma in the right liver lobe. A/B: T2w MRI and pre-interventional contrastenhanced CT: white arrow shows a metastasis from renal cell carcinoma in the left liver lobe prior to treatment by interstitial brachytherapy. C/D: Planning CT with indicated CTV (red line), catheter (marked in red) and isodose lines. E/F: Follow up MRI (E) and CT (F) after 6 months: Size reduction of the previously treated lesion in the left liver lobe (white arrow).

Interventional technique and irradiation. $\mathrm{iBT}$ is an ablative radiation technique used in various inner organs, that utilizes single fraction radiation by an Iridium 192 source with a nominal activity of $10 \mathrm{Ci}$. The source is inserted into the target volume via percutaneously implanted catheters that are placed under imageguidance with a minimal invasive intervention under local anesthesia (lidocaine) and analgosedation (midazolam and fentanyl). The interventional technique has been described elsewhere in detail $(14,17,18)$. The quantity and arrangement of the catheters used was determined by the anatomy of the target lesion.

After catheter positioning, a contrast-enhanced CT scan using a breath-holding technique or an MRI was obtained to document correct catheter positioning and to plan irradiation. Therefore, by this treatment plan the target volume was defined precisely as gross tumor volume (GTV) and as clinical target volume (CTV). Furthermore, organs at risk (OAR; e.g. duodenum) were delineated by the interventional radiologist and the radiooncologist.

Since the ends of the catheters were secured to the skin with a suture, the tip of the catheter was presumably in a fixed position, and CTV could be directly adopted as the planning target volume (PTV). In the next step, dose calculation was performed using the obtained dataset form Oncentra-Masterplan (Oncentra ${ }^{\circledR}$ Brachy treatment planning system, Elekta AB, Stockholm, Sweden) and the calculated isodose lines were controlled and adapted slice by slice.

The prescribed reference dose for our patients was 15 Gy and defined as the minimum dose enclosing the complete CTV (D100). Depending on OARs located in the close proximity to the CTV the D100 had to be lowered. Furthermore, in order to preserve liver function no more than $33 \%$ of the liver parenchyma was supposed to be irradiated with more than 5 Gy (19).
After irradiation, the catheters were removed and the puncture channels were sealed using thrombogenic material (e.g. Gelfoam ${ }^{\circledR}$; Pfizer Inc., New York, NY, USA). Figure 1 illustrates the interventional technique.

Follow-up. All patients were scheduled for clinical, laboratory and imaging follow-ups (contrast-enhanced whole-body CT and gadolinium-enhanced MRI of the liver) every 3 months after iBT. We assessed local tumor control (LTC) and progression-free survival (PFS) by employing RECIST criteria (RECIST version1.1) on the MRI scans (20). LTC was defined as decreasing or stable presentation of the target lesion after iBT. Overall survival (OS) was calculated from the date of ablation to death. Adverse events were defined according to the 'Common Terminology Criteria for Adverse Events' (CTCAE version 4.03) (21).

Study design and statistical analysis. We retrospectively collected the data from our internally database ASENA ${ }^{\circledR}$ (LoeScap Technology $\mathrm{GmbH}$ ). Primary endpoints were LTC and safety; secondary endpoints were OS and PFS. The results were analyzed in a non-randomized and retrospective approach and statistical analysis was performed using with IBM SPSS (IBM Corp. Released 2013. IBM SPSS Statistics for Windows, Version 22.0. Armonk, NY: IBM Corp). LTC, OS and PFS were calculated using the Kaplan-Meier estimation. Safety was assessed descriptively.

\section{Results}

Mean diameter of the target lesions was $2.9 \mathrm{~cm}$ (range $=0.7$ $13.9 \mathrm{~cm})$. Due to their size and location, 25 lesions were 


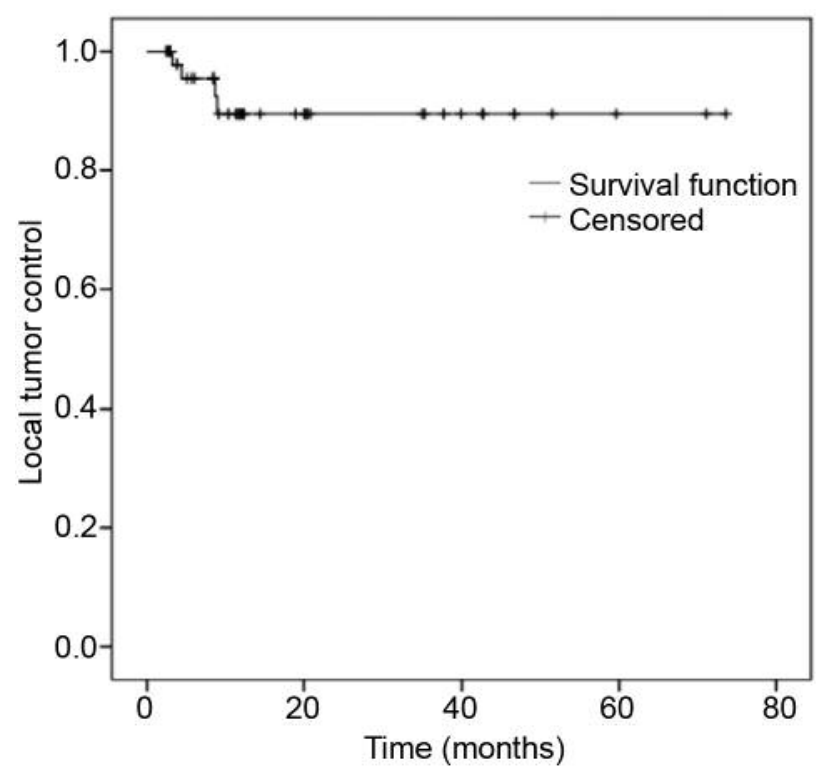

Figure 2. Local tumor control after iBT of all treated $m R C C$.

treated using MRI scans (mean diameter $=1.6 \mathrm{~cm}$; range $=0.5$ $4.8 \mathrm{~cm}$ ), and for 29 lesions CT-guidance was used. A median of 2 lesions (range $=1-12$ lesions) per patient was treated, however, in each patient not more than 5 lesions were apparent and treated in one session. The high number is explained by repeated ablations in the same patient due to progressive disease. On average, the patients underwent 2.2 interventions (range $=1-5$ ); in five patients, local ablation was completed after one session, while nine patients underwent 2-5 sessions due to multiple lesions or progressive disease.

A mean of 2.0 catheters (range $=1-9$ ) was used per patient to achieve a sufficient dose application. The median administered D100 was 16.1 Gy (range=6.5-27.4 Gy). No OARs in the vicinity of the CTV were irradiated in excess of the critical value. The mean irradiation time was $27.8 \mathrm{~min}$ (range $=7.0-92.3 \mathrm{~min}$ ).

Hospital stay varied from 3 to 13 days with a mean of 5.3 days (median 5.0 days). We report four cases of asymptomatic hepatic hemorrhage (classified as grade 1-2 adverse event, according to CTCAE 4.03) and one asymptomatic pleural hemorrhage (grade 1); neither transfusion nor an intervention was required in these cases. In one patient, we observed increased levels of systemic inflammation markers (C-reactive protein, and leukocytosis) without fever or additional symptoms, and administration of i.v. antibiotics (ciproflaxacin and metronidazole) led to a rapid normalization. No severe adverse events (grade 3 or more) and no chronic or late toxicities were reported.

The median follow-up time was 10.2 months (range=2.473.6 months). During the follow-up period we observed 4

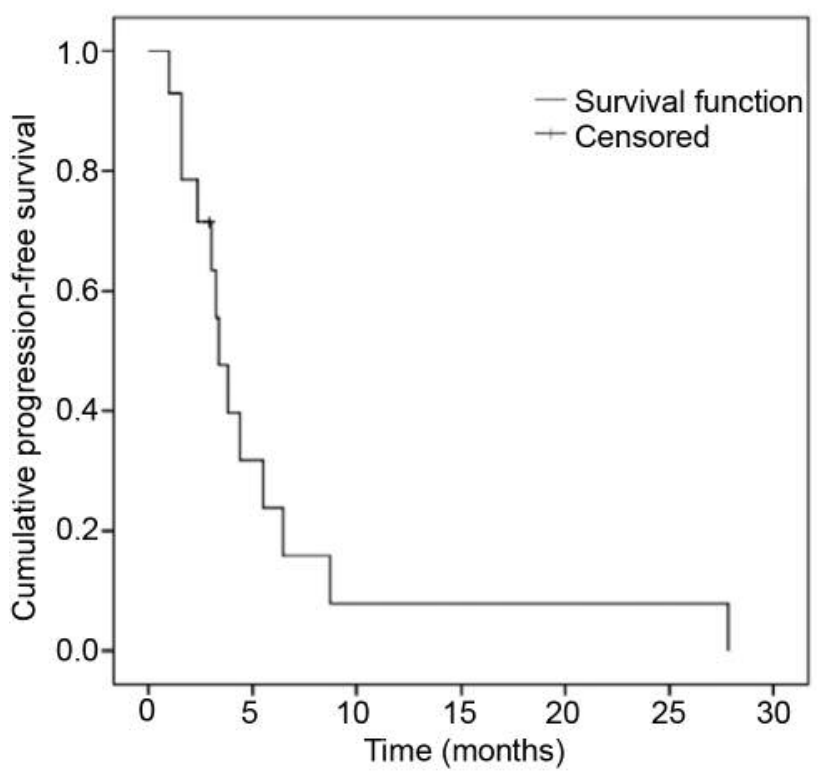

Figure 3. Progression-free survival of patients with mRCC after iBT.

local recurrences in 54 treated target lesions (in a period of 3.3-8.7 months after iBT), resulting in an LTC rate of $92.6 \%$ in the Kaplan-Meier analysis (Figure 2). The mean diameter of the recurrent lesions was $2.1 \mathrm{~cm}$ (range $=1.2-3.4 \mathrm{~cm}$ ) covered with a median D100 of 17.0 Gy (range=15.6-19.5 Gy). Recurrence was reported in a period of 3.2-9.0 months after iBT (median 6.6 months).

Within the follow-up period 13 out of 14 patients showed systemic progressive disease, resulting in a median PFS of 3.4 months (range $=1.0-27.8$ months) (Figure 3).

In the period between local ablation and systemic progression, 7 patients received anticancer therapy: i.e. systemic treatment (2/7 sunitinib) and local ablation of newly diagnosed metastases $(5 / 7$ patients were treated with a total of 7 extrahepatic interventions: 5 BT, 2 RFA).

The median OS was 51.2 months (range=10.2-81.5 months) (Figure 4), however, at the date of censoring, 6 patients of the analyzed cohort were still alive.

In the analyzed cohort, we report that 3 patients survived for 51.5, 64.8 and 81.5 months after iBT.

\section{Discussion}

Approximately $30 \%$ of the patients with RCC display distant metastasis at initial presentation, whereas another $30 \%$ of the patients develop metastatic spread after nephrectomy, primarily to the lung, lymph nodes, bone, liver, adrenal gland, and brain (22). In general, mRCC to the liver portrays a poor prognosis, with a median OS of 7.6-12 months that is shorter, compared to the OS of patients with metastases to other sites $(23,24)$. For 


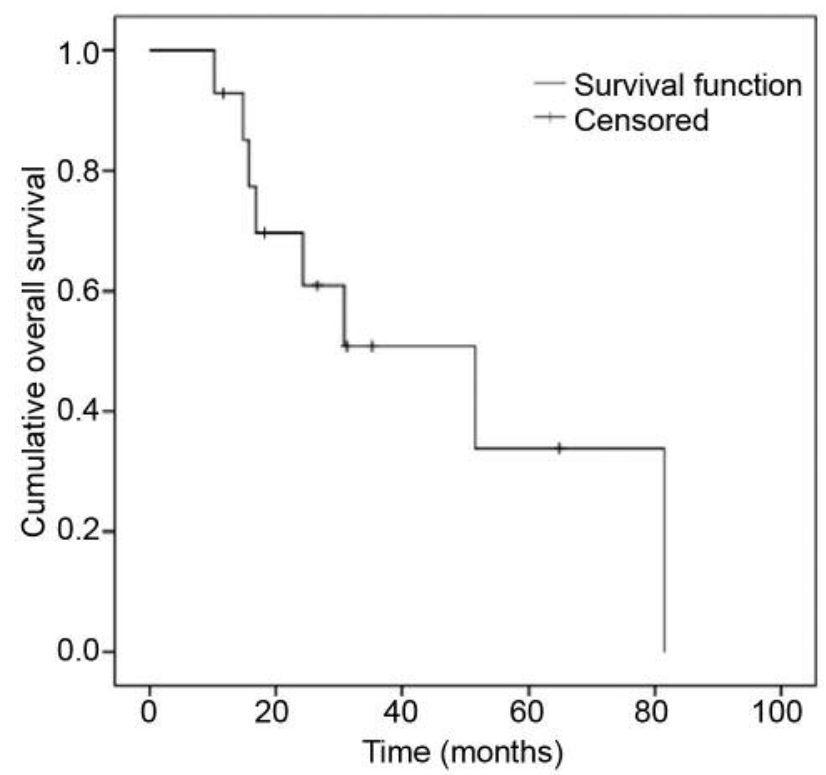

Figure 4. Graph shows overall survival of all patients with mRCC ablated by interstitial brachytherapy.

the patients with metastatic disease, the landscape of therapy has evolved enormously over the past two decades on the basis of an improved understanding of the molecular biology of RCC. Prior to 2005, therapy consisted mainly of immunotherapy, with agents such as interleukin-2 and interferon-a, resulting in an OS of around 1 year for patients with $\mathrm{mRCC}$. With the introduction of multiple targeted therapies primarily directed at VEGF (i.e. axitinib, bevacizumab, pazopanib, sorafenib and sunitinib) or at the mammalian target of rapamycin (mTOR; i.e. everolimus and temsirolimus) the median survival improved immensely to approximately 2.5-3 years (25). Recenty, second-line treatment has been modified after a prolonged OS was shown in two randomized, phase-3 trials for cabozantinib (tyrosine kinases inhibitor=TKI) and nivolumab (programmed death-1 inhibitor): each compared to everolimus in patients with disease progression after previous VEGFR tyrosine-kinase inhibitor treatment. The results showed an improved median OS of 21.4 months versus 16.5 months and 25 months versus 19.6 months, respectively $(26,27)$.

However, despite impressive antitumor effects, reduction of the quality-of-life might occur due to treatment-related severe adverse events, such as diarrhea, fatigue, palmarplantar erythrodysesthesia syndrome or anemia, for instance in the studies mentioned above grade 3 or worse adverse events occurred in $19 \%$ of the patients receiving nivolumab and in $39 \%$ of the patients treated with cabozantinib as well as in $37-40 \%$ of the patients in the everolimus group. This fact might be especially important in patients with limited tumor burden (i.e. oligometastatic disease) and few tumorrelated symptoms.
Therapeutic alternatives for these selected patients focus on local treatment of the oligometastatic spread. However, international guidelines, like European Society for Medical Oncology (ESMO), state that no general recommendation can be given as to whether a patient should be referred for local treatment of metastases or not, but metastasectomy and other local treatment strategies, such as conventional radiotherapy or stereotactic body radiotherapy (SBRT), can be considered and carried out for selected patients after a multidisciplinary review (11). A systematic review of 16 studies reporting on 2350 patients investigated the benefits and harms of various local treatments in any organ for patients with $\mathrm{mRCC}$, suggesting that patients treated with complete metastasectomy have better survival and symptom control than patients treated with no or incomplete ablation (12). Whereas surgical resection is the method of choice in oligometastatic colorectal liver metastases, evidence for surgical resection of $\mathrm{mRCC}$ to the liver is less available. A metanalysis of 10 studies regarding surgical management of RCC liver metastases found a median OS ranging from 16 to 142 months. Also, morbidity and mortality rates ranged from $18.2-57.1 \%$ and $0-31 \%$, respectively, however, complications were not reported in $3 / 10$ studies (28).

The study of Hau et al. was not included in the metanalysis. They reported that a group of patients who received TKI therapy immediately after metastasectomy had a median OS of 98 versus 40 months in the surgery-only group. However, morbidity was reported to be $28.5 \%$ with major complications occurring in $19.9 \%$ of the patients. Furthermore, microscopically complete- R0 status could be achieved in $85,7 \%$ (29). Similarly, Stief et al. also reported R0 status in $85 \%$ of the patients with a mean OS of 16 months after resection, high mortality rate of $31 \%$ and significant morbidity in $23 \%$ (30). Therefore, these findings of variable safety and efficacy combined with significant morbidity and mortality, as well as the limited prognosis even after R-0 resection, emphasize that this procedure strongly depends on careful patient selection.

Additionally, the latest results of a phase 3 trial (CARMENA) showed that sunitinib alone was not inferior to cytoreductive nephrectomy followed by sunitinib in patients with mRCC. More precisely, the median OS was 18.4 months in the sunitinib-alone group and 13.9 months in the nephrectomy-sunitinib group (31). According to the authors, avoiding surgery can provide benefit for the patients, in terms of avoiding surgical complications and therefore, prevent a possible delay of the start of systemic treatment, possibly accounting for the results.

Alternatively, iBT provides a safe and minimally invasive approach. As stated in the literature, grade 3-4 toxicities - i.e. bleeding, requiring angiographic embolization - are reported to occur in up to $2 \%$ of the patients undergoing local ablation of liver lesions $(13,14,18,32)$. In our study, we did not 
observe major complications (grade 3 or worse) associated to the procedure in the post-interventional period or during the follow-up period. Accordingly, the mean hospital stay of our patients was 5.0 days, whereas, for instance, Hau et al. reported a median hospital stay of 18.7 days after surgery (29).

Limited data are available on the efficacy and outcome of patients with hepatic mRCC undergoing tumor ablation, including iBT, radiofrequency ablation (RFA), stereotactic body radiation (SBRT) or conventional radiotherapy. More precisely, to our knowledge, no study exists evaluating the efficacy or safety of iBT in patients with $\mathrm{mRCC}$ to the liver.

Similarly, data for SBRT in the treatment of hepatic metastases of RCC are scarce. However, one study analyzed 58 patients with RCC and metastases to any site, including 3 patients with liver lesions. The authors reported a LTC rate of $90.2 \%$ at 12 and 18 months, a median OS of 28.4 months and an overall low complication rate with no grade 3 or worse adverse events (33). Another investigation by Stinauer et al. reports a median OS of 22.2 months for 13 patients with $\mathrm{mRCC}$ to any organ. Also, the cumulative LTC rate was $88 \%$ since 17 patients with melanoma were also included in the study (overall 11 patients with hepatic metastases) and only one late grade 3 adverse event was observed (34).

Numerous studies have assessed the effect of RFA in the treatment of focal liver tumors; however, the method has primarily been used and evaluated for the ablation of hepatocellular carcinoma and colorectal liver metastases. For instance, Yun et al. treated 25 patients with non-colorectal liver metastases and no hepatocellular carcinoma $(1 / 25$ diagnosed with RCC) with a tumor size of $0.5-5 \mathrm{~cm}$ and found local tumor progression in 12 of 37 lesions $(32 \%)$ during a median follow up period of 18.8 months (35). In the study by Langan et al., a group of 10 patients diagnosed with $\mathrm{mRCC}$ to the liver was treated with liver resection and 8 patients underwent RFA of hepatic metastases. The median OS for the surgery group was 24 months compared to 15.6 months in the RFA group (36). Mortality was nil, but morbidity was not reported for surgery and RFA separately.

Comparable to iBT, the potential benefits of RFA include reduced morbidity and mortality, low cost compared with standard surgical resection, as well as the ability to treat nonsurgical candidates. However, this thermal method has well known technical limitations; it is effective for tumor sizes $<5 \mathrm{~cm}$ and the cooling effects arising from the vicinity of large vessels could possibly lead to an incomplete ablation. Moreover, adverse events may occur due to the proximity to heat sensitive organs (e.g. bile duct, ureter, liver hilum). In contrast, iBT remains free from those constraints.

In our study we report an LTC rate of $92.6 \%$ during a follow-up period of 10.2 months with no grade 3 or worse adverse events. These results are comparable to the efficacy after ablation of primary and secondary liver malignancies, demonstrating LTC rates of $95 \%$ and $88.3 \%$ after 12 months, respectively $(13,15,19)$ or to the excellent LTC rate of $97.4 \%$ after the ablation of metastasized anal squamous cell carcinoma (14).

As stated above, prognosis for patients with RCC and liver metastases is poor. Consequently, the role of surgery and local therapy remains controversial. The selection of patients who might benefit from a multidisciplinary approach is essential.

In this study, we report a median OS of 51.2 months ranging from 10.2-81.5 months with three long-time survivors with OS of 51.5, 64.8 and 81.5 months, one of these patients being alive at the date of censoring. Compared to some literature reviews, the survival rates observed in our study are not inferior to those after surgery, RFA or SBRT $(28,29,33$, $34,36)$. Our results emphasize that selected candidates might benefit from an ablative approach even in a metastatic setting.

Limitations of our study are its retrospective nature and the low number of patients, as well as the short follow-up that is due to the poor prognosis of the study cohort. Furthermore, the analyzed patient population was heterogeneous and comprised of patients heavily pretreated with various agents that failed to provide therapy prior to $\mathrm{iBT}$ and in part treated with anticancer therapy after iBT.

However, according to the literature, few data are available on local ablation of mRCC to the liver and therefore, despite its limitations, our study illustrates that $\mathrm{iBT}$ is an additional well-tolerated and feasible ablative technique in the toolbox for mRCC. Moreover, our findings suggest that the procedure might improve the OS of selected, oligometastatic patients.

In conclusion, our results confirm that interstitial brachytherapy is a safe and particularly effective procedure with an excellent local control rate for selected patients with metastatic renal cell cancer to the liver.

\section{Conflicts of Interest}

The Authors have no conflicts of interest to declare.

\section{Authors' Contributions}

All Authors made substantial contributions to conception and design of the study, acquisition of data, or analysis and interpretation of data, drafting the article or revising it critically for important intellectual content. Jazan Omari and Maciej Pech approved the final version of the manuscript to be published.

\section{References}

1 Siegel RL, Miller KD and Jemal A: Cancer statistics, 2018. CA Cancer J Clin 68(1): 7-30, 2018. PMID: 29313949. DOI: 10.3322/caac. 21442

2 Capitanio U, Bensalah K, Bex A, Boorjian SA, Bray F, Coleman J, Gore JL, Sun M, Wood C and Russo P: Epidemiology of renal cell carcinoma. Eur Urol 75(1): 74-84, 2018. PMID: 30243799. DOI: $10.1016 /$ j.eururo.2018.08.036 
3 Capitanio U and Montorsi F: Renal cancer. The Lancet 387(10021): 894-906, 2016. PMID: 26318520. DOI: 10.1016/S0140-6736(15)00046-X

4 Ljungberg B: The role of metastasectomy in renal cell carcinoma in the era of targeted therapy. Curr Urol Rep 14(1): 19-25, 2013. PMID: 23212738. DOI: 10.1007/s11934-012-0293-6

5 Lalani A-KA, McGregor BA, Albiges L, Choueiri TK, Motzer R, Powles T, Wood C and Bex A: Systemic treatment of metastatic clear cell renal cell carcinoma in 2018: Current paradigms, use of immunotherapy, and future directions. Eur Urol, 2018. PMID: 30327274. DOI: 10.1016/j.eururo.2018.10.010

6 Motzer RJ, Hutson TE, Tomczak P, Michaelson MD, Bukowski RM, Rixe O, Oudard S, Negrier S, Szczylik C, Kim ST, Chen I, Bycott PW, Baum CM and Figlin RA: Sunitinib versus interferon alfa in metastatic renal-cell carcinoma. N Engl J Med 356(2): 115124, 2007. PMID: 17215529. DOI: 10.1056/NEJMoa065044

7 Sternberg CN, Davis ID, Mardiak J, Szczylik C, Lee E, Wagstaff J, Barrios CH, Salman P, Gladkov OA, Kavina A, Zarbá JJ, Chen M, McCann L, Pandite L, Roychowdhury DF and Hawkins RE: Pazopanib in locally advanced or metastatic renal cell carcinoma: Results of a randomized phase iii trial. J Clin Oncol 28(6): 10611068, 2010. PMID: 20100962. DOI: 10.1200/ JCO.2009.23.9764

8 Motzer RJ, Hutson TE, Cella D, Reeves J, Hawkins R, Guo J, Nathan P, Staehler M, de Souza P, Merchan JR, Boleti E, Fife $\mathrm{K}$, Jin J, Jones R, Uemura H, De Giorgi U, Harmenberg U, Wang J, Sternberg CN, Deen K, McCann L, Hackshaw MD, Crescenzo R, Pandite LN and Choueiri TK: Pazopanib versus sunitinib in metastatic renal-cell carcinoma. N Engl J Med 369(8): 722-731, 2013. PMID: 23964934. DOI: 10.1056/ NEJMoa1303989

9 Gore ME and Larkin JM: Challenges and opportunities for converting renal cell carcinoma into a chronic disease with targeted therapies. Br J Cancer 104(3): 399-406, 2011. PMID: 21285971. DOI: $10.1038 /$ sj.bjc.6606084

10 Jonasch E, Gao J and Rathmell WK: Renal cell carcinoma. BMJ 349: g4797-g4797, 2014. PMID: 25385470. DOI: 10.1136/bmj. g4797

11 Escudier B, Porta C, Schmidinger M, Rioux-Leclercq N, Bex A, Khoo V, Gruenvald V and Horwich A: Renal cell carcinoma: Esmo clinical practice guidelines for diagnosis, treatment and follow-up. Ann Oncol 27(5): v58-v68, 2016. PMID: 27664262. DOI: $10.1093 / \mathrm{annonc} / \mathrm{mdw} 328$

12 Dabestani S, Marconi L, Hofmann F, Stewart F, Lam TB, Canfield SE, Staehler M, Powles T, Ljungberg B and Bex A: Local treatments for metastases of renal cell carcinoma: A systematic review. Lancet Oncol 15(12): e549-561, 2014. PMID: 25439697. DOI: $10.1016 / \mathrm{S} 1470-2045(14) 70235-9$

13 Collettini F, Lutter A, Schnapauff D, Hildebrandt B, Puhl G, Denecke T, Wust P and Gebauer B: Unresectable colorectal liver metastases: Percutaneous ablation using ct-guided high-dose-rate brachytherapy (ct-hdbrt). Rofo 186(6): 606-612, 2014. PMID: 24407711. DOI: $10.1055 / \mathrm{s}-0033-1355887$

14 Heinze C, Omari J, Othmer M, Hass P, Seidensticker M, Damm R, Ricke J, Pech M and Powerski MJ: Image-guided interstitial brachytherapy in the management of metastasized anal squamous cell carcinoma. Anticancer Res 38(9): 5401-5407, 2018. PMID: 30194195. DOI: 10.21873/anticanres.12870

15 Mohnike K, Wieners G, Schwartz F, Seidensticker M, Pech M, Ruehl R, Wust P, Lopez-Hanninen E, Gademann G, Peters N, Berg T, Malfertheiner P and Ricke J: Computed tomography-guided high-dose-rate brachytherapy in hepatocellular carcinoma: Safety, efficacy, and effect on survival. Int J Radiat Oncol Biol Phys 78(1): 172-179, 2010. PMID: 20056348. DOI: 10.1016/j.ijrobp.2009. 07.1700

16 Bretschneider T, Mohnike K, Hass P, Seidensticker R, Goppner D, Dudeck O, Streitparth F and Ricke J: Efficacy and safety of image-guided interstitial single fraction high-dose-rate brachytherapy in the management of metastatic malignant melanoma. J Contemp Brachytherapy 7(2): 154-160, 2015. PMID: 26034497. DOI: $10.5114 /$ jcb.2015.51095

17 Ricke J and Wust P: Computed tomography-guided brachytherapy for liver cancer. Semin Radiat Oncol 21(4): 287-293, 2011. PMID: 21939858. DOI: 10.1016/j.semradonc.2011.05.005

18 Bretschneider T, Ricke J, Gebauer B and Streitparth F: Imageguided high-dose-rate brachytherapy of malignancies in various inner organs - technique, indications, and perspectives. J Contemp Brachytherapy 8(3): 251-261, 2016. PMID: 27504135. DOI: $10.5114 /$ jcb.2016.61068

19 Ricke J, Wust P, Stohlmann A, Beck A, Cho CH, Pech M, Wieners G, Spors B, Werk M, Rosner C, Hanninen EL and Felix R: Ctguided interstitial brachytherapy of liver malignancies alone or in combination with thermal ablation: Phase i-ii results of a novel technique. Int J Radiat Oncol Biol Phys 58(5): 1496-1505, 2004. PMID: 15050329. DOI: 10.1016/j.ijrobp.2003.09.024

20 Eisenhauer EA, Therasse P, Bogaerts J, Schwartz LH, Sargent D, Ford R, Dancey J, Arbuck S, Gwyther S, Mooney M, Rubinstein L, Shankar L, Dodd L, Kaplan R, Lacombe D and Verweij J: New response evaluation criteria in solid tumours: Revised recist guideline (version 1.1). Eur J Cancer 45(2): 228247, 2009. PMID: 19097774. DOI: 10.1016/j.ejca.2008.10.026

21 Institute NC: Common terminology criteria for adverse events (ctcae) v4.03. June 14, 2010.

22 Motzer RJ, Jonasch E, Agarwal N, Bhayani S, Bro WP, Chang SS, Choueiri TK, Costello BA, Derweesh IH, Fishman M, Gallagher TH, Gore JL, Hancock SL, Harrison MR, Kim W, Kyriakopoulos C, LaGrange C, Lam ET, Lau C, Michaelson MD, Olencki T, Pierorazio PM, Plimack ER, Redman BG, Shuch B, Somer B, Sonpavde G, Sosman J, Dwyer M and Kumar R: Kidney cancer, version 2.2017, nccn clinical practice guidelines in oncology. J Natl Compr Canc Netw 15(6): 804834, 2017. PMID: 28596261. DOI: 10.6004/jncen.2017.0100

23 Hamada S, Ito K, Kuroda K, Sato A, Asakuma J, Horiguchi A, Seguchi K and Asano T: Clinical characteristics and prognosis of patients with renal cell carcinoma and liver metastasis. Mol Clin Oncol 3(1): 63-68, 2015. PMID: 25469271. DOI: 10.3892/ mco. 2014.432

24 Naito S, Yamamoto N, Takayama T, Muramoto M, Shinohara N, Nishiyama K, Takahashi A, Maruyama R, Saika T, Hoshi S, Nagao K, Yamamoto S, Sugimura I, Uemura H, Koga S, Takahashi M, Ito F, Ozono S, Terachi T, Naito S and Tomita Y: Prognosis of japanese metastatic renal cell carcinoma patients in the cytokine era: A cooperative group report of 1463 patients. Eur Urol 57(2): 317-326, 2010. PMID: 19136199. DOI: $10.1016 /$ j.eururo.2008.12.026

25 Pal SK, Choueiri TK, Karam JA and Heng DY: Metastatic renal cell carcinoma: Contending with a sea change in therapy. Urol Oncol 33(12): 507-508, 2015. PMID: 26584741. DOI: 10.1016/j.urolonc.2015.10.005

26 Choueiri TK, Escudier B, Powles T, Tannir NM, Mainwaring PN, Rini BI, Hammers HJ, Donskov F, Roth BJ, Peltola K, Lee 
JL, Heng DYC, Schmidinger M, Agarwal N, Sternberg CN, McDermott DF, Aftab DT, Hessel C, Scheffold C, Schwab G, Hutson TE, Pal S and Motzer RJ: Cabozantinib versus everolimus in advanced renal cell carcinoma (meteor): Final results from a randomised, open-label, phase 3 trial. Lancet Oncol 17(7): 917-927, 2016. PMID: 27279544. DOI: 10.1016/S1470-2045(16)30107-3

27 Motzer RJ, Escudier B, McDermott DF, George S, Hammers HJ, Srinivas S, Tykodi SS, Sosman JA, Procopio G, Plimack ER, Castellano D, Choueiri TK, Gurney H, Donskov F, Bono P, Wagstaff J, Gauler TC, Ueda T, Tomita Y, Schutz FA, Kollmannsberger C, Larkin J, Ravaud A, Simon JS, Xu LA, Waxman IM and Sharma P: Nivolumab versus everolimus in advanced renal-cell carcinoma. N Engl J Med 373(19): 18031813, 2015. PMID: 26406148. DOI: 10.1056/NEJMoa1510665

28 Pikoulis E, Margonis GA and Antoniou E: Surgical management of renal cell cancer liver metastases. Scand J Surg 105(4): 263 268, 2016. PMID: 26929295. DOI: 10.1177/1457496916630644

29 Hau HM, Thalmann F, Lübbert C, Morgul MH, Schmelzle M, Atanasov G, Benzing C, Lange U, Ascherl R, Ganzer R, Uhlmann D, Tautenhahn H-M, Wiltberger G and Bartels M: The value of hepatic resection in metastasic renal cancer in the era of tyrosinkinase inhibitor therapy. BMC Surg 16(1): 49-49, 2016. PMID: 27444582. DOI: 10.1186/s12893-016-0163-0

30 Stief CG, Jahne J, Hagemann JH, Kuczyk M and Jonas U: Surgery for metachronous solitary liver metastases of renal cell carcinoma. J Urol 158(2): 375-377, 1997. PMID: 9224306.

31 Méjean A, Ravaud A, Thezenas S, Colas S, Beauval J-B, Bensalah K, Geoffrois L, Thiery-Vuillemin A, Cormier L, Lang H, Guy L, Gravis G, Rolland F, Linassier C, Lechevallier E, Beisland C, Aitchison M, Oudard S, Patard JJ, Theodore C, Chevreau C, Laguerre B, Hubert J, Gross-Goupil M, Bernhard JC, Albiges L, Timsit MO, Lebret T and Escudier B: Sunitinib alone or after nephrectomy in metastatic renal-cell carcinoma. $\mathrm{N}$ Engl J Med 379(5): 417-427, 2018. PMID: 29860937. DOI: 10.1056/NEJMoa 1803675
32 Geisel D, Denecke T, Collettini F, Grieser C, Wust P, ThussPatience P, Hamm B and Gebauer B: Treatment of hepatic metastases from gastric or gastroesophageal adenocarcinoma with computed tomography-guided high-dose-rate brachytherapy (cthdrbt). Anticancer Res 32(12): 5453-5458, 2012. PMID: 23225451.

33 Franzese C, Franceschini D, Di Brina L, D'Agostino Giuseppe R, Navarria P, Comito T, Mancosu P, Tomatis S and Scorsetti M: Role of stereotactic body radiation therapy for the management of oligometastatic renal cell carcinoma. J Urol 201(1): 70-76, 2019. PMID: 30179619. DOI: 10.1016/j.juro.2018.08.049

34 Stinauer MA, Kavanagh BD, Schefter TE, Gonzalez R, Flaig T, Lewis K, Robinson W, Chidel M, Glode M and Raben D: Stereotactic body radiation therapy for melanoma and renal cell carcinoma: Impact of single fraction equivalent dose on local control. Radiation Oncology 6(1): 34, 2011. PMID: 21477295. DOI: $10.1186 / 1748-717 X-6-34$

35 Yun BL, Lee JM, Baek JH, Kim SH, Lee JY, Han JK and Choi BI: Radiofrequency ablation for treating liver metastases from a non-colorectal origin. Korean J Radiol 12(5): 579-587, 2011. PMID: 21927559. DOI: 10.3348/kjr.2011.12.5.579

36 Langan RC, Ripley RT, Davis JL, Prieto PA, Datrice N, Steinberg SM, Bratslavsky G, Rudloff U, Kammula US, Stojadinovic A and Avital I: Liver directed therapy for renal cell carcinoma. J Cancer 3: 184-190, 2012. PMID: 22558019. DOI: $10.7150 /$ jca. 4456
Received March 21, 2019

Revised April 12, 2019

Accepted April 15, 2019 